\title{
The challenge of discussing energy facts and climate change
}

\author{
Christoph Buchal $(*)$ \\ Forschungszentrum Jülich GmbH - Jülich, Germany \\ Universität zu Köln - Köln, Germany
}

Summary. - The experiences of numerous lectures about the present situation of the global energy supply and the possible future developments are presented in the form of 10 statements. Although the physics of the atmosphere, climate history and climate change are relatively easy to present, it becomes very difficult or even emotional, if the far-reaching economic curtailments and the proposed laws to limit the emissions are discussed. The subject of an efficient and constructive global energy policy is strongly controversial even within the scientific community and the best pathways into a peaceful emission-free global energy future are passionately disputed. In general, the technical and financial dimensions of the proposed global change to renewable energies turn out to be hardly conceivable. Most frequently, the spirit of the presentation, for instance optimistic, pessimistic or even cynical, creates a stronger impression on the audience than the bare facts beyond comprehension.

\section{1. - The benefit of the present climate change discussions}

Presently there are far more than 100 books plus countless publications, news and opinions on climate change flooding the public and the media. By now, nearly everybody should have obtained a certain personal opinion on this matter. A recent UN assembly

$\left(^{*}\right)$ E-mail: c.buchal@fz-juelich.de 
judges climate change as the most important challenge of mankind. The young Greta Thunberg ("The house is on fire! I wish, that you get in panic!") presently stands out as the leading person of the now worldwide "Fridays for Future" movement. Simply, the warnings of an upcoming catastrophic global warming are omnipresent. On the other hand, realistic and quantitative solutions of the truly global problem of energy related fossil emissions remain to be seen. In the context of a fact-based technical lecture on energy, it is not helpful to doubt the warnings and conclusions of climate science or to discuss the remaining uncertainties of climate projections, deny their implications or even to promote fossil energy technologies in a tone of "continue business as usual".

Instead, it is quite helpful to use this debate as a powerful wake up call to explain the history and importance of reliable and ecological energy systems. The audience will easily understand, that climate science provides a complex diagnostic picture of the past and the present times. Science also proposes a wide spectrum of possible future projections and associated biological scenarios — but climate science completely fails to provide a realistic therapy against global warming except the obvious and rather easy call for global energy austerity and the urgent abdication of fossil energy use. Unfortunately, there is absolutely no way back to the pre-industrial times, and the road ahead into a past-fossil age seems long, ambitious, very expensive and most demanding.

There is no doubt, that the intense use of fossil fuels such as coal, oil and natural gas has brought mankind to the present level of progress and life standards - but at the same time we observe a growing level of $\mathrm{CO}_{2}$ and other greenhouse gases in the atmosphere [1]. These global developments are primarily due to the achievements of technology together with scientific discoveries. As a consequence and especially in view of the growing global population, most probably only science and technology can offer a realistic potential to find new ways into an energy future without the use of fossil energy. In the present ecological conflict with frequent calls for immediate and drastic actions it is worthwhile to return to a rather old truth. Independent of all present arguments, the fossil supplies remain truly limited and will eventually come to an end, although the big companies keep discovering new oil and gas reserves [2-4]. One might think of fostering more nuclear power plants, breeding reactors or future fusion experiments. They are important and hold a far-reaching potential, but in view of their present status of energy production, they will not be able to replace the dominant fossil supplies substantially within the next decades, due to the overwhelming extent of the present oil, gas and coal use, which provides approximately $85 \%$ of the world energy supply.

It is estimated, that the coal reserves will last for approximately 200 years. Also for many decades to come, crude oil will remain the most important source of energy. At the present rate of production, crude oil might become somewhat depleted after 2100 . Completely replacing oil, gas and coal constitutes an enormous challenge. The powerful global infrastructure for oil drilling, production, refineries, international distribution by pipelines and tankers and its use for transportation, mobility, air traffic as well as chemistry constitutes an immense investment [5]. This infrastructure embraces the entire 
globe. It has been established and strengthened over more than a century and cannot be easily replaced within any short span of time. However, it will have to disappear eventually or it will have to be converted and merge into a sustainable technology. Here lies the huge potential of slowly introducing synthetic fuels based on renewable energies, see sect. 9 (case $d)$.

It is the message of this paper and of my public talks to first explain the basis of our general living conditions, the time needed to establish the technology and infrastructure of the present world, and secondly, to encourage strong research efforts to advance new energy technologies, because undoubtedly mankind will need them within this 21 st century. This change will not come cheap or easy and probably it will not be rapid. Notwithstanding, new energy techniques are needed under all circumstances.

Unfortunately the currently proposed energy policies will not be able to lower the global emissions quickly to a level which satisfies the "public and political climate goals", because these goals have been set overly optimistic and too high. Nevertheless, energy $\mathrm{R} \& \mathrm{D}$ is an urgent and indispensable investment into the future, because the simple concepts of austerity and energy savings or energy allocation quota and limits alone will not suffice. Worse, strictly enforced "social controls" for individual energy use may become outright destructive for the stability of our liberal democracies. But we cannot wait, simply sit still and watch what happens. If in the future oil or energy in general would run short unexpectedly quickly on a worldwide scale, a rigorous loss of global life standards, mass migration or even wars over the remaining resources are expected.

We need the courage and determination to improve and restructure our energy systems, even if the climate goals remain out of reach. However, panic is not helpful. Panic is counterproductive. R\&D needs careful long-term planning and pragmatism in a world of divergent interests and vastly different possibilities. Teaching the energy facts honestly and with some optimism should be the responsibility of all knowledgeable scientists.

\section{2. - A world of 11 billion people - or more}

Concerning the present energy demand, the most important factor is the rapid growth of the world population, which amounts to approximately $1 \%$ or 80 million persons per year, see fig. 1 [6]. The associated demand for energy, including coal, oil and natural gas grows even stronger, at a rate of $2.2 \%$ per year. Although the world production of renewable energy (RE) has been increasing by $17 \%$ per year, the RE so far cannot even satisfy the increase of the total global energy demand. The unprecedented growth of population was caused by the progress of science and technology, especially hygiene and medical sciences together with scientific agriculture, which has been able to feed the growing population. It is the growth of the world population, that completely prohibits any attempts to return to the pre-industrial era. In addition, there is very little hope, that the strong growth of the global population will come to a stop or a decrease in the near future. 


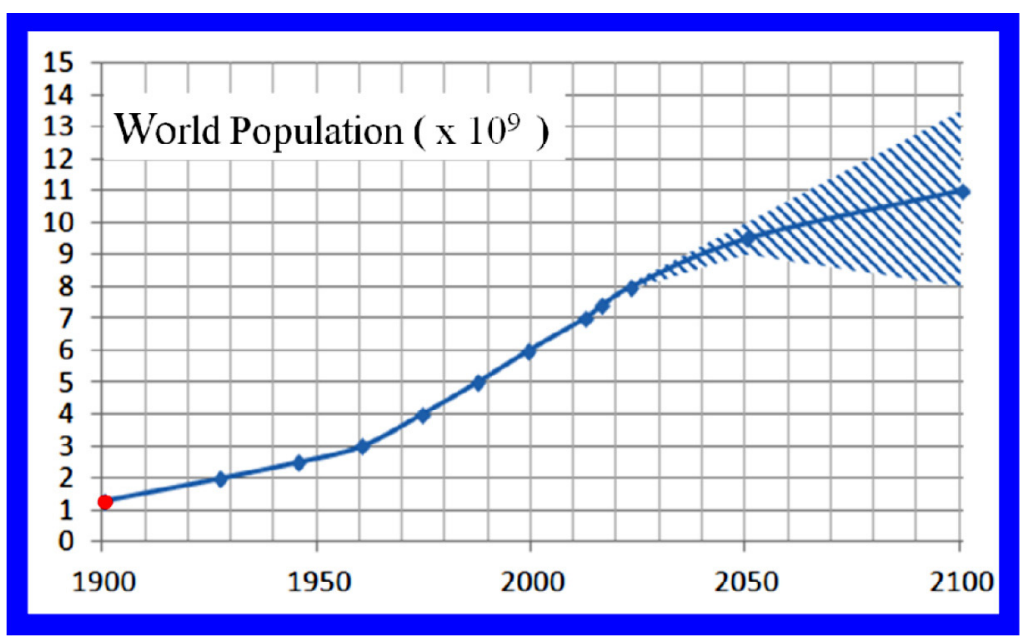

Fig. 1. - The growth of the world population since 1900 and the uncertain future development.

\section{3. - Four industrial revolutions form the key to understanding the developments}

In Roman times, less than 500 million people lived on earth. It took about 2000 years to double that number. Not before 1800 the world population reached 1 billion people. At that time coal and steam engines started to change the methods of manufacturing and an increasing number of people found jobs in industrial factories. This first industrial revolution is still going strong, since the annual global use of coal remains at an all times high — presently especially for electrical power generation.

Starting around 1880, a second industrial revolution developed with the discovery of another energy supply: petroleum. It was perfectly suited for the newly invented internal combustion engines, for cars and trucks, later also for airplanes. In parallel, electrical power started its conquest of the world. Also this Second Industrial Revolution is still going strong, as our world keeps running on coal, oil and electricity.

Even a little earlier the information revolution had started with the electrical telegraph. Telephones, radios, TVs, computers, the internet and mobile units followed. Today, machine learning, artificial intelligence, robotics and quantum computing are at the frontline of the Third Industrial Revolution. Together with electrical machinery and lighting this Third Industrial Revolution clearly demonstrates, that mankind most probably will need electricity for all future times to come. The use of coal, petroleum (fossil crude) and natural gas will end sooner or later - but the production of electrical power must go on forever. The very rapid success of computers and electronics has created a certain conviction within the general public, that nearly everything is possible in a short time span by pushing science and technology. But this hope is misleading, because information and energy belong to very different scientific classes. Information can be 
created, processed, distributed or even completely annihilated — but all forms of energy and their conversions have to follow the strict laws of thermodynamics. The possibilities to produce or harvest "energy on demand" turn out to be tedious and rather limited.

This brings us to the great challenge of the fourth industrial revolution, which is starting now. Electrical power should become available to everybody and everywhere - as soon as possible and without any use of fossil fuels. In our plans and dreams for the coming century, we will strive towards a "renewable energy based all-electrical society" - hopefully without any loss of comfort and with a high standard of living for all mankind. This defines a great peaceful transformation of the entire world. Obviously, this upcoming fourth global industrial revolution is an unresolved challenge of extreme importance for the present and future generations.

\section{4. - Food energy by photosynthesis will remain the basis of all life}

Our most important energy supply is provided by our food, consisting of fat, vegetable oils, protein, sugar and starch. Today 7 billion persons have access to sufficient food, but 800 million persons are undernourished. Looking back to 1960, approximately the same number of persons were undernourished or starving, but only 2 billion well fed - while the total world population amounted to 3 billion persons only [7-10]. This stunning increase of agricultural production was achieved without any significant growth of the agricultural land area. This well known "Green Revolution" is due to three factors: scientific fertilization with artificial nitride fertilizers, phyto-sanitary improvements and plant breeding [11].

Let us briefly look at the energy provided by our food. The basic energy need for a human is equivalent to an average power of $100 \mathrm{~W}[12]$. This is approximately the power of a single candle flame. For an entire day, it adds up to an energy need of $2.4 \mathrm{kWh}$, which is equal to $8640 \mathrm{~kJ} /$ day (or in older units: $2060 \mathrm{kcal} /$ day). A quarter of a liter of plant oil could supply a complete day's basic energy need of $2,4 \mathrm{kWh}$. Please note, that we use the units of Watts or $\mathrm{kWh}$ as well to denote the energy provided by food and not only to denote electrical energy.

These numbers provide a useful benchmark for comparison to the vastly higher energy demand of technical engines. For example, car engines typically produce between 50 and $150 \mathrm{~kW}$ of mechanical power. For a distance of $100 \mathrm{~km}$ at reasonable driving habits a car needs $15-25 \mathrm{kWh}$ of mechanical energy. Using a typical combustion engine of $33 \%$ efficiency, this corresponds to $45-75 \mathrm{kWh}$ of fuel energy for $100 \mathrm{~km}$. At $10 \mathrm{kWh} /$ liter of Diesel fuel (or bio-Diesel or plant oil!), this amounts to 4.5 to 7.5 liters of fuel for $100 \mathrm{~km}$.

The basic biochemical equation that describes food production seems very simple at first glance, but many mysteries of the biochemistry of photosynthesis remain unsolved. An analogous technical process has not yet been established on a large scale. It would be great, if an all-technical reactor could use sunlight plus $\mathrm{CO}_{2}$ plus water to deliver basic glucose, or even carbohydrates for real food. It is a wonderful and fantastic scientific goal to develop an efficient future technical photosynthesis process in order to 
provide bio-energy on a large technical scale without a negative impact on the environment. Unfortunately, at present the additional cultivation of bio-energy plants for technical use, especially bio-fuel for cars, leads to a catastrophic new impact on land use. The demand for new farm land creates massive jungle clearance fires in the tropics with horrible consequences for the involved biosphere and the global atmosphere as well.

Remembering that a car with its $50-150 \mathrm{~kW}$ engine is much more greedy for energy than its driver $(100 \mathrm{~W})$, any hope for a substantial contribution from bio-energy to power the global mobility demands of planes, ships and cars turns out simply pointless.

\section{5. - Fossil energies provide our significantly better life}

The Industrial Revolutions and the availability of relatively cheap and concentrated fossil energy and new machines have liberated mankind from most of the very hard manual labor. It created our present standard of living, allowing for longer education times for the youth, leading to a tremendous growth and progress in science and technology, making worldwide travel and commerce easily possible and obviously resulted in a less hazardous, healthier and much longer life. From 1900 to today the average life span increased from 40 to 80 years.

On the other hand, mankind became dependent on a sufficient energy supply. On average, this amounts to a primary energy supply of about $120 \mathrm{kWh}$ per person and day in most industrialized countries of the world. This can be expressed as $5 \mathrm{~kW}$ of average primary energy supply. The world average is $2.5 \mathrm{~kW}$. On the other hand, the numbers for the US are approximately $240 \mathrm{kWh}$ per person and day or $864 \mathrm{MJ} /$ day or $10 \mathrm{~kW}$ as the average continuous use of primary energy supply per person.

In Germany, the primary energy use consists of $4 \mathrm{~kg}$ coal, $3 \mathrm{~m}^{3}$ natural gas, 5 liters oil products, $0,02 \mathrm{~g}{ }^{235} \mathrm{U}$, plus $14 \%$ of renewable energy (RE). These numbers include the daily share of $20 \mathrm{kWh}$ of electrical power. Please note, that the technical energy demand is approximately 50 times higher than that for human food.

Fossil energy has become the largest worldwide traded commodity. Today $85 \%$ of the global energy supply is provided by crude oil, coal and natural gas. This holds for most nations and has become crucial for the wealth of nearly all nations worldwide. So far, only $15 \%$ of the primary energy is provided by renewable energy (RE) sources. Therefore it is unrealistic to switch off the fossil supplies quickly and without sufficient alternative energy sources to replace them.

Fossil energies changed the entire world and led to new life styles, new social structures, longer life spans, larger cities. Fossil energy powers the machines, which grow and transport the food for the growing world population.

Unfortunately, yesterdays blessings and solutions are becoming today's and tomorrow's curse. The $\mathrm{CO}_{2}$ level in the atmosphere is rising and the call for a major reduction of emissions is undisputed by most scientists and citizens. 


\section{6. - Our hopes rest on carbon-free energy sources}

Most of our hope for the future rests on the development of non-fossil energy sources $[12,13]$. Several well established technologies are already available: dams for hydropower, wind turbines, photovoltaic, geothermal (ground) heat, solar heat plants, wave and tidal energy sources, and the use of biomass for biogas or heat. So far, burning wood remains the major energetic use of biomass. In addition to these renewable energy sources, nuclear energy is another nearly emission-free technology. Presently nuclear energy provides $6 \%$ of the global demand for primary energy and there are more than 300 new nuclear plants in an early planning phase or under construction. Therefore nuclear power plants could continue to provide approximately the same share of energy in the next decades. In a more distant future fusion may become another option.

For Germany and many other industrial nations, a significant increase of the number of wind turbines and PV panels seems the only realistic pathway to generate more RE power. One obstacle of this type of RE power production lies in the huge number of needed wind turbines and PV panels. Is there enough land area for so many wind turbines within the densely populated industrial countries?

It remains a completely unsolved quantitative problem to increase the RE production by a factor of 8 to 10 within Germany. Ever more wind turbines are not accepted by many residents and environmentalists.

Therefore it is useful to evaluate the geographical differences with respect to harvesting RE. It is also worth remembering, that presently the lion's share of the energy supply for Germany and many other European nations is not produced within the country, but it is bought on the world market and imported. It has become a wide spread and naive mistake to assume, that the renewable energies must be harvested directly inside the countries.

Instead, the task of reducing the global emissions should promote a worldwide market of renewable energies, which should be established step for step in parallel to the world market of oil, gas and coal. The technical problems are solved for the long-distance trade of electrical power and also for the storable forms of renewable energy, for example hydrogen gas or liquid hydrogen or for the many variations of synthetic fuels.

\section{7. - Where to harvest RE most efficiently?}

Wind turbines at coastal regions or even offshore offer 2000 to 4000 full load hours of power production per year (1 year $=8760$ hours). PV harvests in Germany are around 1000 hours per year. This number can be doubled in sunny desert areas, as for instance in Spain or North Africa.

Accepting the different geographical realities of the globe, we strongly advise considering the RE supply of Europe in the same terms as we consider the European crude oil supply presently: import the energy from those areas where it is available. With the presently available RE technology and without drastically expanding nuclear power, Europe will be unable to develop a self-sufficient, autarkic RE system. 
Instead, Europe needs to invest in large scale RE production fields worldwide with the appropriate energy conversion technologies and to establish the worldwide RE trade.

Clearly any intelligent plan for RE production must primarily aim at those areas where the best production efficiencies are available. For Europe, these are in the Mediterranean area of Europe, but in addition also in North Africa for solar energy [13]. Wind generally is best harvested along the coastal lines, but also in some windy deserts, for example in Mongolia. Unfortunately, the previous failure of the DESERTEC-program due to political unrest and fighting in North Africa has set a sad example, but this does not change the overall plan for a better future. Instead, we must foster hope and stability for a peaceful cooperation, which offers opportunities for both the industrial and the developing nations. Large future wind and solar farms would provide a valuable economic investment, permitting the export of valuable RE from presently less developed countries and areas, even deserts.

\section{8. - Energy storage and transport becomes a crucial challenge}

One of the worst obstacles for the wide spread use of wind and PV is the fluctuating, intermittent energy output of wind and PV installations. There is no realistic large scale storage for electricity available except pumped water storage reservoirs. In contrast to the Swiss, Austrian or Norwegian situation, the German potential is not encouraging. To cover the expected down times for wind and sun within Germany, the capacity of the German dams would have to be increased by orders of magnitude from the present value of $40 \mathrm{GWh}$, as the average power demand in Germany presently amounts to $68 \mathrm{GW}$. Therefore water storage for hydropower is no sufficient option for Germany. The only realistic alternative is the long-distance transfer of electrical power by high-voltage dc transmission lines or the conventional transport of synthetic fuels, which have been produced without fossil energy, see below.

Long-distance transport of electrical power has been made possible by modern semiconductor technology. It is now possible, to convert high voltage ac $\rightarrow \mathrm{dc}$ or $\mathrm{dc} \rightarrow \mathrm{ac}$ at voltage levels of up to 800000 volts [14]. The European Long-Distance Operators ENTSO-E incorporate HVDC into their grid, because it permits the transport of electrical energy over many thousand kilometers with relatively low losses [15]. In China, the new Xiangjiaba-Shanghai UHVDC line spans $2000 \mathrm{~km}$ and transports $6.4 \mathrm{GW}$ with an excellent efficiency of $93 \%$. This demonstrates the technical potential for very long-distance electrical power transport across all Europe and North Africa, or over even further distances. As an extreme example for an extended future power grid, an $8000 \mathrm{~km}$ link between Mongolia and France could provide a transmission efficiency of $75 \%$. This offers an interesting long-term perspective for mitigating the fluctuations of power production due to the correlations within the European sun or wind patterns.

\section{9. - Different ways to use RE energy for mobility}

Presently oil products are needed for most vehicles, ships and airplanes. One class of exceptions are the electrical vehicles, as discussed below. One might also think of the 
well-known biological movers, as horses, oxen, camels and donkeys, which rely on quasisolid natural carbohydrate energy carriers plus drinking water. So even the farmers always had to calculate the relative amounts of growing "animal feed" or "human food".

A large fraction of the global oil production, approximately $40 \%$, is used for mobility and transport. Indeed more than $95 \%$ of the energy needed for transport comes from liquid carbohydrates like kerosene, diesel, gasoline, liquefied gas (propane) or heavy oils. Nearly $90 \%$ of these fuels are directly distilled from crude oil. CNG (compressed natural gas, methane) still plays a minor role, although its use produces $20 \%$ less $\mathrm{CO}_{2}$ than diesel or gasoline.

The already mentioned "all-electrical future" of the industrial societies, based on wind, PV, nuclear, hydropower and a few other sources so far turns out to be rather incompatible with the classical demands for mobility and transport. In fact, it is difficult to give up the conventional liquid fuels for the transport sector. In particular airplanes depend on the superior energy density of kerosene $(10 \mathrm{kWh} /$ litre or $12 \mathrm{kWh} / \mathrm{kg})$. So far, the worldwide $\mathrm{CO}_{2}$ emissions of the transportation sector remain at a constant high or even increasing level in spite of significant improvements in the engine efficiencies, because the global demand for transport and mobility keeps growing.

However, there are several ways to electrify the transport sector to a very large extend. This is important, because we have to focus on the long-term objective of using RE electrical power instead of fossil fuels. We present the four main lines of thought, although there are numerous combinations, called "hybridizations" [5, 16-19].

a) So far, only one sub-sector of transport has been successfully electrified to a major extent: trains, subways, trams and cable cars. Most of them are moving on tracks, being continuously connected to a power plant by overhead lines or similar. Considering the efficiency, these vehicles are the heroes of electrical transport. Because they do not need heavy batteries with the associated charging and discharging losses, their efficiency (engine $\rightarrow$ wheels) may reach $90 \%$. In fact, electrical motors are optimal suited for vehicles with their high starting torque, very high maximum rpm, no need for clutches and gearboxes, no local emissions and minimal demands for maintenance. Note that the electrical interconnection losses from the power plant to the railway are not included in the efficiency numbers, because these losses are inevitable for all uses of electrical power and vary according to the local situation.

b) For small vehicles, especially moderate range cars and light trucks, battery powered electrical vehicles $(\mathrm{BEV})$ are becoming more and more popular. Charging and discharging the battery offers a $90 \%$ efficiency for each step. The total efficiency (charge $\rightarrow$ discharge $\rightarrow$ engine $\rightarrow$ wheels) drops to approximately $75 \%$. The burden of carrying the battery's heavy weight will further reduce the efficiency. The total efficiency is not bad, but the maximum capacity of a battery limits the range significantly. In addition, the charging times for a $50 \mathrm{kWh}$ battery, permitting approximately a $300 \mathrm{~km}$ drive, are at best around $30 \mathrm{~min}$ for high power chargers $(\sim 100 \mathrm{~kW})$ and many hours for household wall boxes $(\sim 10 \mathrm{~kW})$. Amongst the European political authorities, BEV are considered as the appropriate solution for emission control. Therefore BEVs are 
generally classified as Zero Emission Vehicles. The European manufacturers are strongly forced to develop and fabricate BEVs. All this will result in a noticeable reduction of the emissions only in the long run, after the European power production will be converted to truly emission-free electricity. In this respect, the many nuclear power plants of France are setting the standards.

c) Electrical power can be converted to hydrogen by the electrolysis of water with $70 \%$ efficiency. Hydrogen can be stored and transferred to electrical cars, which are fitted with a high-pressure tank and a fuel cell system (FCV). The fuel cell converts hydrogen to electricity with $60 \%$ efficiency. A typical hydrogen storage pressure is 700 bar, and the refueling of a FCV takes only a few minutes. The typical range between refueling stops of a FCV is more than $400 \mathrm{~km}$. However, this system requires a completely different infrastructure, which forms a certain handicap towards the rapid introduction of FCV. Of course, the system also suffers from the efficiency loss due to the various conversion steps: RE power $\rightarrow$ electrolysis $\rightarrow$ hydrogen compression $\rightarrow$ hydrogen transport $\rightarrow$ FCV refueling by hydrogen $\rightarrow$ FCV fuel cell $\rightarrow$ e-motor $\rightarrow$ wheels. One estimates at most a 30\%-35\% efficiency for this overall chain. Presently, FC are strongly promoted in Germany, first for fixed base transportation, later also for long-distance trucks. Buses frequently return to their depot with their own hydrogen "gas station". They do not suffer from the low number of hydrogen refueling stations in Germany (60 in 2019). Several cities are now running or ordering FC buses and some small train lines are converted to FC $[20,21]$.

d) My favorite concept for the future rests upon the fabrication of artificial synthetic fuels from RE electricity. In simple terms, hydrogen gas from electrolysis plus carbon from $\mathrm{CO}_{2}$ sources or from the air are converted to synthetic fuels with superior combustion properties. This "synfuel" is transported and distributed by the existing infrastructure of tankers and gas stations. Synfuel can be introduced smoothly and slowly, maintaining the entire conventional distribution system in operation without excessive investments. Eventually it should be used by optimized conventional combustion engines and turbines of airplanes, trucks and cars. This approach is not disruptive and keeps the entire distribution chain plus the worldwide fleet of planes, ships and vehicles in operation. Due to the unsurpassable energy content of kerosene and diesel fuel (10 kWh/liter), it offers optimal conditions especially for airplanes, heavy trucks and heavy machinery. On the other hand, for the fabrication of this fuel a completely new supply plant structure must be erected. It will be comparable in size to the present oil refineries. Unfortunately, the efficiency of the entire chain "RE power $\rightarrow$ hydrogen $\rightarrow$ carbohydrates $\rightarrow$ distribution $\rightarrow$ combustion engines $\rightarrow$ wheels" is reduced to $15-20 \%$. However, the fuel is a well known liquid, which is easily transported and stored. The entire technology is compatible with the present infrastructure and the vehicles and planes. Synfuel can be introduced slowly and stepwise without any disruptions of the existing infrastructure. The production of synfuel will cost 2-3 Euro/liter [20]. Of course, the high price is a serious obstacle for a quick introduction. On the other hand, any global decarbonization project will become expensive, if conventional fuels are phased out $[22,23]$. 


\section{0. - Summary}

On a global scale, it will take time to give up the fossil energies and to transform the energy system completely to renewable sources. The wider perspective of global RE energy export and import comes rather naturally and is strongly supported by longdistance high-voltage dc transport of electrical energy as well as liquid or compressed hydrogen or, even better, synthetic fuels. Our hopes rest primarily in wind energy, $\mathrm{PV}$, nuclear power and hydro to supply the world of tomorrow. Besides information and knowledge of the important facts and numbers, the well known virtues of courage and realism, patience and tolerance will be needed to further develop the science and technology in order to replace the fossil energies step by step. But most of all this new energy age will require a peaceful international collaboration at global scale. Without peace, there will be no global RE development projects and no global market. Peace forms the basis for our energy future.

The author gratefully acknowledges many stimulating discussions with Gerd Wolf, Juelich, and Jef Ongena, Brussels, and with all the friends at DPG and EPS. He thanks the Italian Physical Society especially for the organization and the marvellous scientific atmosphere at the Varenna convention.

\section{REFERENCES}

[1] www.ipcc.ch.

[2] https://www.bp.com/content/dam/bp/business-sites/en/global/corporate/pdfs/ energy-economics/statistical-review/bp-stats-review-2019-full-report.pdf.

[3] https://corporate.exxonmobil.com/Energy-and-environment/Looking-forward/ Outlook-for-Energy.

[4] US Energy Information Agency, Annual Energy Outlook 2019 with projections to 2050 (2019) https://www.eia.gov/outlooks/aeo/pdf/aeo2019.pdf.

[5] Kalghatgi G., "Is it really the end of internal combustion engines and petroleum in transport?" Appl. Energy, 225 (2018) 965, http://www2.eng.ox.ac.uk/engines/ sigpresentations/kalghatgi.

[6] https://en.wikipedia.org/wiki/World_population

[7] https://ourworldindata.org/hunger-and-undernourishment.

[8] Rosling Hans, Factfulness (Flatiron Books, New York) 2018.

[9] https://en.wikipedia.org/wiki/Hunger.

[10] https://www.gdch.de/fileadmin/downloads/Netzwerk_und_Strukturen/Fachgruppen/ Seniorexperten/PDF/Tagungen/4_SEC_Jahrestreffen/4SECJT_Qaim.pdf.

[11] https://en.wikipedia.org/wiki/Green_Revolution.

[12] Hermans Jo, Energy Survival Guide (Leiden University Press) 2011.

[13] Düren Michael, Understanding the Bigger Energy Picture - DESERTEC and Beyond, https://www . springer.com/de/book/9783319579658.

[14] https://en.wikipedia.org/wiki/High-voltage_direct_current.

[15] https://vision2030.entsoe.eu/wp-content/uploads/2019/11/entsoe_fp_vision_ 2030_web.pdf. 
[16] Buchal Ch. and Sinn H.-W., "Decarbonizing Mobility - Thoughts on an Unresolved Challenge", Eur. Phys J. Plus, 134 (2019) 599.

[17] Stolten D. and Emonts B. (Editors), Hydrogen Science and Engineering, Vols. 1 and 2 (Wiley-VCH, Weinheim) 2016.

[18] Stolten D., Samsun R. C. and Garland N. (Editors), Fuel Cells (Wiley-VCH, Weinheim) 2016.

[19] "Hyundai Motor and H2 Energy to bring the world's first fleet of fuel cell electric trucks into commercial operation" (2019) https://www.hyundai.co.nz/hyundai-motor-andh2-energy-to-bring-the-world-s-first-fleet-of-fuel-cell-electric-trucksinto-commercial-operation-.

[20] https://www.cleanthinking.de/brennstoffzellen-busse-hool-beliefert-koelnwuppertal/.

[21] https://en.wikipedia.org/wiki/Hydrail.

[22] Agora Verkehrswende, Agora Energiewende and Frontier ECONOMics, "The Future Cost of Electricity-Based Synthetic Fuels" (2018) https://www . agora-energiewende.de/fileadmin2/Projekte/2017/SynKost_2050/ Agora_SynKost_Study_EN_WEB.pdf.

[23] Wilson I. A. G. and Styring P., "Why Synthetic Fuels are necessary in Future Energy Systems", Front. Energy Res. (2017) https://doi.org/10.3389/fenrg.2017.00019/. 